\title{
低出力 $\mathrm{CO}_{2}$ レーザーによる血管吻合の臨床応用
}

Clinical application of vascular anastomosis by low output $\mathrm{CO}_{2}$ laser

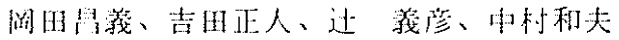 \\ Masayoshi Okada, MD, Masato Yoshida, MD, Yoshihiko Tsuji, MD, Kazuo Nakamura, MD. \\ 神三大学经学激第2外科 \\ Department of Surgery, Division Il , \\ Kobe University School of Medicine
}

\begin{abstract}
In vascular surgery, there is a great problem to keep high patency rate after reconstructive surgery especially for small-caliber vessels. For resolving of this problem, laser was applied to make vascular anastomosis with few stay sutures. Optimal conditions of vascular anastomosis by lasing were $20 \sim 40 \mathrm{~mW}$ in output and $6 \sim 12 \mathrm{sec} / \mathrm{mm}$ in irradiation time. Histological examination revealed good healing at the sites of anastomosis by laser. And adequate intensity of the anastomotic sites by laser was also confirmed. On the basis of excellent experimental studies, laser was employed to make vascular anastomosis in 91 patients with intermittent claudication and anginal pain and renal failure. The first successful clinical application was carried out in 44 year-old female patient with renal failure on 21 st February 1985 in the world. Coronary artery bypass surgery was also performed clinically by using low output $\mathrm{CO}_{2}$ laser. All patients are now doing well without any complications throughout the laser. The longest survivor has been passed 4years 9months after laser surgery. Laser application in this field was useful and inevitable to make vascular anastomosis especially for small-caliber vessels.
\end{abstract}

緒 管

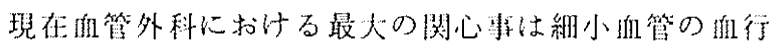

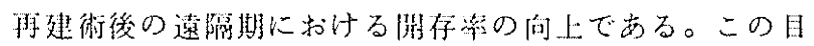
的のために人工血管や縫合系あるいは抗凝扣薬などにい たる非極的な開発や改桹が加えられている。蒋者らはい かに多方面に和たる研究が加えられても、やはり释合禾 による影恝が最も大きいため、释合采の使用を可及的少 なくするのが効果的ではないかと考え、レーザーの応用 に着目した。

近年の医用レーザーの間発にはめざましいものがある が、著者らは数あるレーザーの中で最も組紻への侵䌘が 少ない $\mathrm{CO}_{2}$ を選扒し、血管吻合に応用した。

系統的な基礎的研究を開始して好成果を收めたので、

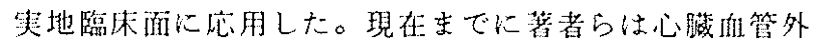
科領域でレーザーを115症例に応用した。最長の followup症例は4年9力月になるが、全例健在である(表1)。

以下、著者らの自験例を中心に低出力レーザーを用い た血管吻合法に閶する手技、邂灾、問題点などについて 報告する。

1）血管吻合時の至適なレーザー照射条件

まず、レーザー出力と照射時間とを種々組み合わせ動 脈壁に対する組織反応を種々检誩した。その結果、レー

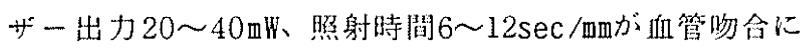

\section{表 1 心搭血管外科におけるレーザーの臨床応用}

\begin{tabular}{c|c}
\hline Method & No. of Case \\
\hline 1) & 1 \\
2) $\begin{array}{l}\text { Vascular anastomosis } \\
\text { (including CABG } 8 \text { cases) }\end{array}$ & 91 \\
3) Laser angioplasty for the \\
coronary artery \\
4) Laser angioplasty for the \\
peripheral artery
\end{tabular}

際して至適条件であることが判明した。この条件で数本 の支持系を使用し、 $\mathrm{CO}_{2} レ$ ー゙ーによる组管吻合（阔明 洼)の可能なことを立証し、未梢動脈の血行雨建衔をは じめ冠動脈バイバスにも十分レーザーで吻命が可能であ

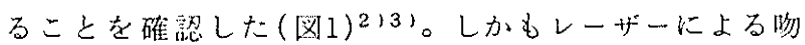

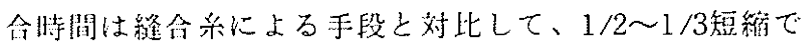
きる事䒠觉確解した。

2）レーザーによる血管吻合の適応とそのポイント

值径4吅以下の紐小血管の血行再建術にレーザーによ る吻合が最適であると考えられる。綘合系による吻合部 

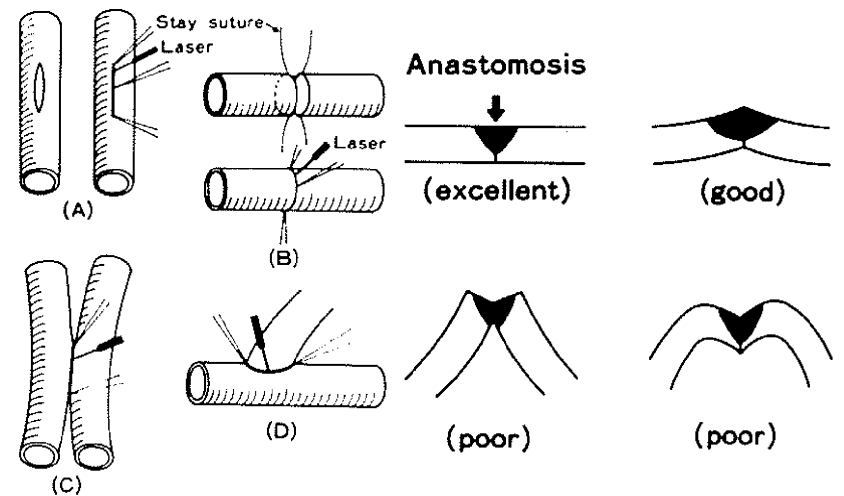

(B)

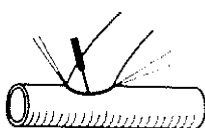

(D)

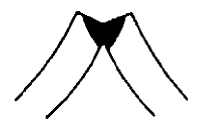

(poor)

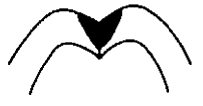

(poor)
図 1 レーザー吻合のボイント

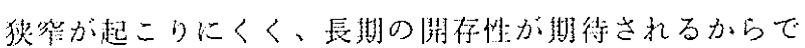
茄る。一方、吻合部に石扊化や高度の便化性病变が存在 する場合には本法の邀応はない。つきに、血管吻合のボ イントについて述べるが、をれは、以下の4点である。 すなわち、、）吻合する牦管の断端を4本位の細い支持系 をかけて密猜させること、b）支持采を軽く率引して吻 弇線上に焦点光をゆっくり照射すること、c）吻合部は dry fieldにすること、などである゙（図2)。
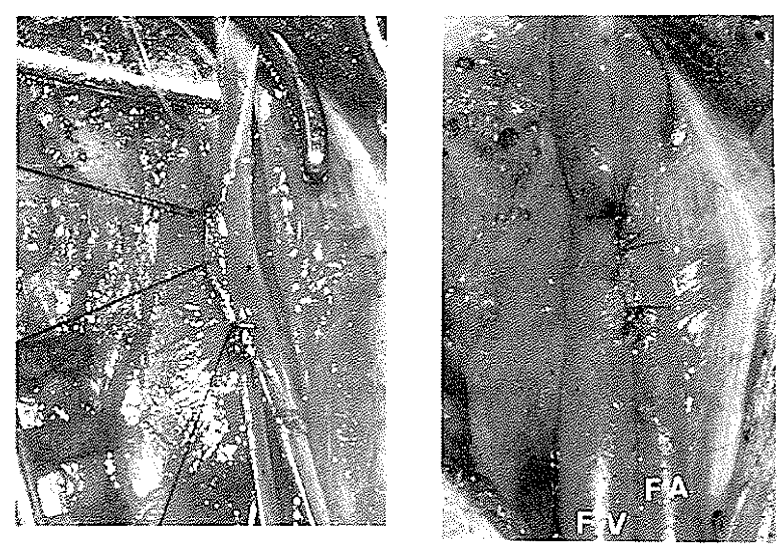

a) 側々吻合

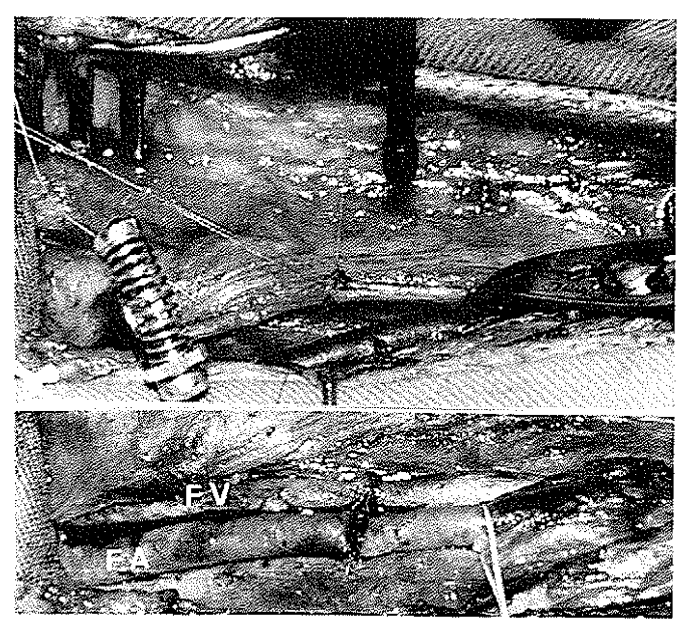

b）端々吻合

図 2 レーザー血管吻合の実際
3）抽管吻合部の強渡

レーザー吻合部の強庭がどの程度保持されているかに ついては多くの注目がよせられている。この点を解明す べく吻合部の酎压試験と抗張力陚験との2つの観点から

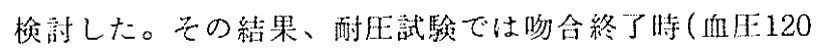

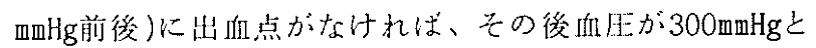
著明に上梸してもほとんど出卹しない事害が判明しだ。

一方、吻合部に加重をかけてその断裂する時点での抗 張力を維合采による吻合部とレーザーによる㽗合部のそ れと対比した。その結果、縫合采による抗張力の平均は

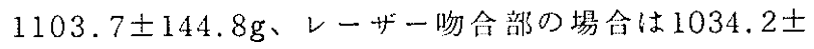
$103.9 \mathrm{~g}$ と闻䔩間に有意差のない事奉が判明し、臨床応用 への可能性が如车に呈示された21。

4) 血管吻合部の組織学的所見

レーザー血管吻合の直後は外膜から中膜にいたる弹力 䋐維やコラーゲンがレーザー熱で融解し、あたかも生体 糊の作用をしている事其が確諗された。ごく初撕には、 部はフィブリン膜で被璋されているが経時的には fibroblastや絬合組織の增生がみられ、2カ月以上にな ると線維性維織が增生し吻合部の焧合が䃨固になってい る所見が確認された。一方、縫合系による吻合部では采 による基物巨細胞がみられ、これが次第に肉芽組絨の增 生を過剩にさせて、折管内腔を狭小化せしめている所見 が呈示され、レーザー吻合部でより良好な嶊合所見がえ られだい。

5）知東例への芯用

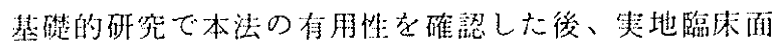
に応用した。現在までにレーザーによる血管吻合は䧗休 例91例（男62例、女 29 例)に奏施された(表2)。年鹤は18 〜80歲(平㚬59藏)であり、血管吻合の条件はレーザー出 力 $30 \sim 50 \mathrm{~mW}$ (平均 $40 \mathrm{~m} W$ )、照射時間38 $360 \mathrm{sec}$ (平均 5.8 $\mathrm{sec} / \mathrm{mm}$ )であった。石网化や硕化件病変が高度であって も限局性の場合には部分的に切除し吻合部断端が来軟珄 となった時点で吻合を開始し、とくに問題にはならな

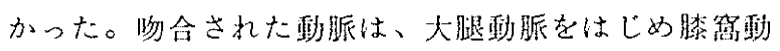
脈、榚骨動脈、㹂動脈、上腕動脈、大腿静脈之多くの部 位にわたっている。吻合方法は端々物合が67ケ所、端例 吻合が45ケ所、側々吻会が1ケ所の計113ケ所であった2い 支持系の閏隔は4〜 $5 \mathrm{~mm}$ 讁切であった。

a）末梢動脈への応用

第1例は昭和60年2月21日、44藏女性例に対して慢性简 不全の治療を目的として行われた枿骨動眽での動・静脈 汤合であった。本轿例は臨床例におけるレーザー血管吻 合の世界最初の成功例であった（図3)。本症例を含め、 その後の臨枺例の報告は1985年5月にフロリダ州のオラ ンドで開催された第5回フメリカレーザー医学会で報告 する機会をえた。この際、臨本経験のないてメりカの医 
師連から多数の質問攻めにあったのを昨今のように賞え ている。現在、術後最長例は4年9ケ月になるが、全例で 吻合部の開存が証明され、血腫や動脈瘤などの合傡症は 認められず、満足すべき成績がえられている(図4)。

\section{表 2 レーザーによる血管吻合の臨床例}

No. of cases: 91 cases (Male 62, Female 29) Age : 18 80 year (mean $59 \mathrm{Y}$ )

\begin{tabular}{c|c}
\hline Site of Anastomosis & No. of Anastomosis \\
\hline Femoral artery (EE) & 63 \\
Femoro-popliteal bypass & 28 \\
(E-S anast. by SVG) & 4 \\
Radial artery-ceph. V.(E-S) & 3 \\
Femoral vein (E-E) & 2 \\
Pop.-popliteal bypass & 1 \\
(E-S anast. by SVG) & 1 \\
Brachial artery (E-E) & 3 \\
Tibial artery (S-S. E-S) & 6 \\
SVG-LAD (E-S) & 2 \\
LIMA-LAD (E-S) & 13 \\
\hline
\end{tabular}

E-E : End-to-end anastomosis

E-S : End-to-side

S-S : Side-to-side
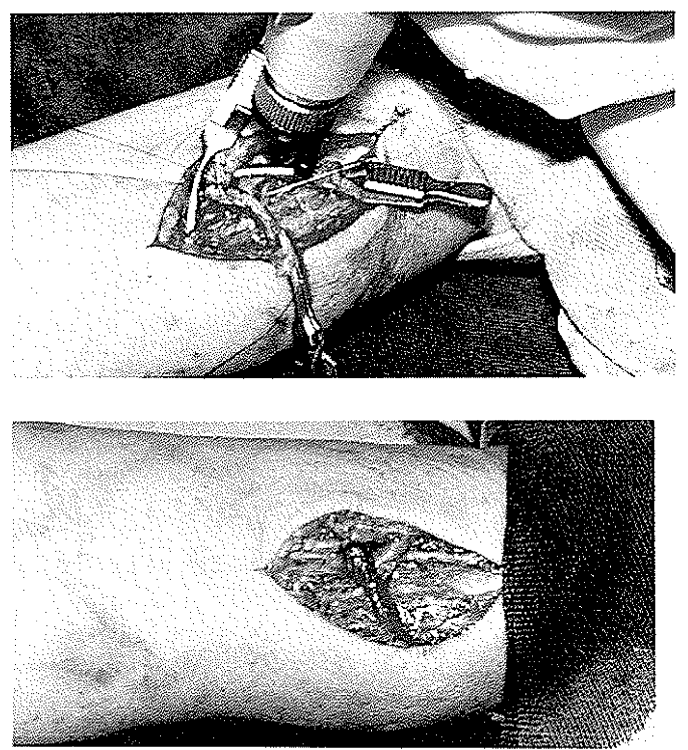

図 3 動・静脈の端僓吻合（44歳、女）
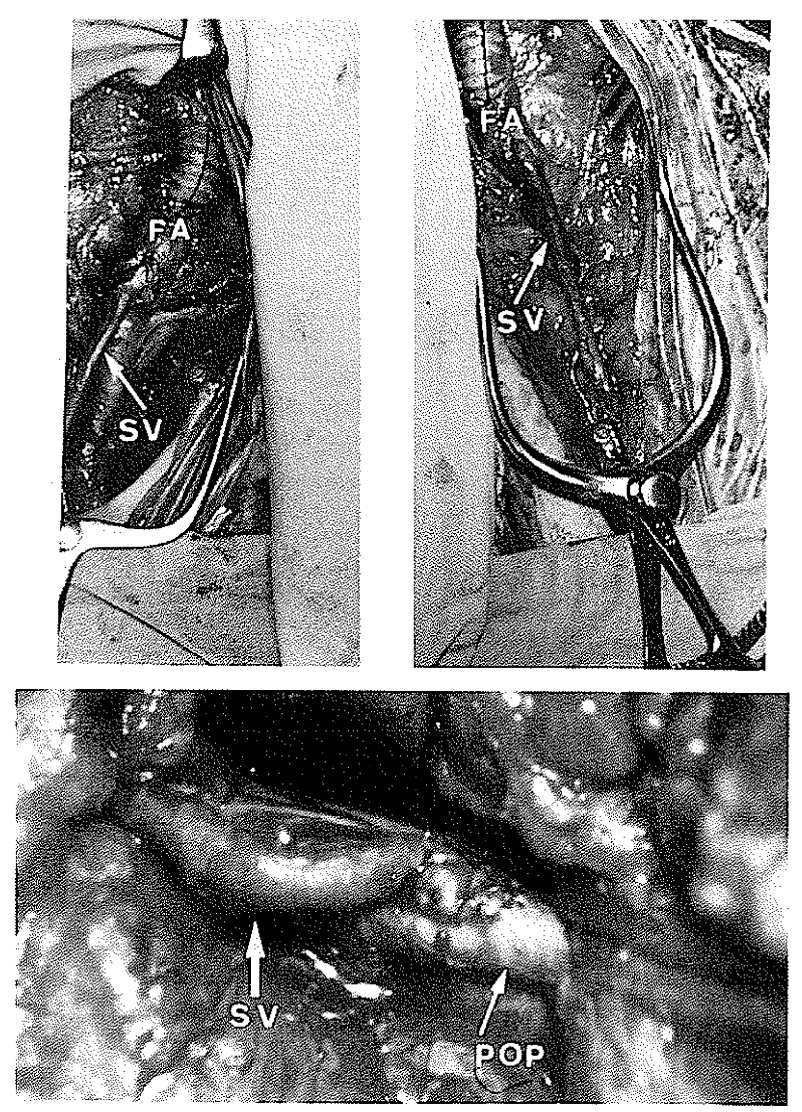

図 4 レーザーによる両側大腿、㮏窝動脈バイバス術 (68 歳、男)

b）冠䧉脈バイバスへの忘用

末梢動脈例で好成繢がえられたので冠犋脈に対しても レーザーが応用されした。現在まで8症例にレーザーが 応用されたが、いずれも左冠動脈前下行枝(LAD)での吻 合であった（表3）。

これら症例吓、與味ある症例5および6を供覧する。症 例 5：39藏、男、心筋椣塞後の狭心放例である。冠動脈 造影上、 $\operatorname{LAD}($ No. $7 、 8)$ 亿 $75 \% 、 \mathrm{CX}$ (No. 13)に $290 \% 、 \mathrm{RCA}$ (No. 2) $90 \%$ 狭算を有することが判明した。手術はNo. 3、13には大伏在静脈を用いるバイパスが行われたが、 LADには内夙動派を用いるレーザー㽛合が施行された（図 $5)$ 。

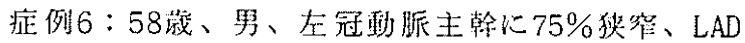
(No. 7) $100 \% 、 C x$ (No. 11、12) K $75 \% 、 90 \% 、 R C A($ No. 2) $100 \%$ 閉塞が認められた。各狭管部に大伏在静脈を用 いる三枝バィパスがLAD、CX(No. 12)、RCA(No. 3)に夷 施されたが、この際LADの吻合にレーザーが使用された

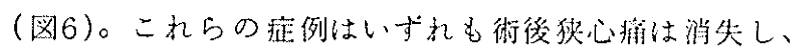
グラフトの造影においても開存が証明された。とくに、 レーザー汤合部での㹟窄所見の諗められないのが、本法 の特色であると考えられた。 
表 3 レーザーによる冠動脈バイバスの臨床例

\begin{tabular}{|c|c|c|c|c|c|c|c|c|c|}
\hline \multicolumn{2}{|c|}{ Caso } & \multirow{2}{*}{$\begin{array}{l}\text { A00 } \\
52\end{array}$} & \multirow{2}{*}{$\frac{\text { Sox }}{M}$} & \multirow{2}{*}{$\begin{array}{c}\text { Symptom } \\
\text { PIA }\end{array}$} & \multicolumn{2}{|c|}{ CAG } & \multirow{2}{*}{$\begin{array}{l}\text { Bypass } \\
\text { LAD } \\
C X \\
D t\end{array}$} & \multirow{2}{*}{\begin{tabular}{|c|}
$\begin{array}{l}\text { Silo of } \\
\text { Ansust. }\end{array}$ \\
LAO \\
(LIMA)
\end{tabular}} & \multirow{2}{*}{$\begin{array}{l}\text { Romatks } \\
\begin{array}{l}40 \mathrm{~mW} .10 \mathrm{~mm} \\
54 \mathrm{sec}\end{array}\end{array}$} \\
\hline 1) & Y. Y. & & & & $\begin{array}{ll}\text { LMT } & \\
\text { LAD } & 16 \\
& \end{array}$ & $\begin{array}{l}9096 \\
99 \% \\
75 \%\end{array}$ & & & \\
\hline 2) & K. N. & 58 & M & UAP & $\begin{array}{ll}\text { LMT } & \\
& (9 \\
\text { RCA } & (3\end{array}$ & $\begin{array}{l}90 \% \\
90 \% 6 \\
50 \%\end{array}$ & $\begin{array}{l}\angle A D \\
C x\end{array}$ & $\begin{array}{l}\text { LAD } \\
\text { (SVG) }\end{array}$ & $\begin{array}{l}40 \mathrm{~mW} . \text { B Bsm, } \\
50 \mathrm{sec}\end{array}$ \\
\hline 3) & T.Y. & 56 & $M$ & UAP & $\begin{array}{lr}\text { LAD } & (6 \\
\text { CX } & 113 \\
\text { RCA } & 12 \\
& 13\end{array}$ & $\begin{array}{r}75 \% \\
100 \% \\
90 \% \\
75 \%\end{array}$ & $\begin{array}{l}\text { LAD } \\
C x \\
\text { RCA }\end{array}$ & $\begin{array}{l}\text { LAD } \\
\text { (SVG) }\end{array}$ & $\begin{array}{l}40 \mathrm{~mW}, 12 \mathrm{sm} . \\
65 \mathrm{soc}\end{array}$ \\
\hline 4) & M. O. & 69 & $M$ & $A P$ & $\begin{array}{lr}\text { LAD } & (6 \\
& 67 \\
& 7 \\
\text { CX } & (13 \\
\text { RCA } & (3\end{array}$ & $\begin{array}{r}75 \% \\
25 \% \\
75 \% \\
100 \%\end{array}$ & $\begin{array}{l}\text { LAD } \\
\text { CX }\end{array}$ & $\begin{array}{l}\text { LAD } \\
\text { (SVG) }\end{array}$ & $\begin{array}{l}40 \mathrm{mw}, 8 \mathrm{~mm}, \\
48 \mathrm{sec}\end{array}$ \\
\hline 5) & T. Y. & 39 & M & PIA & $\begin{array}{l}\text { LAD } 17.8 \\
\text { Cx } \\
\text { ACA }\end{array}$ & $\begin{array}{l}75 \% \\
90 \% 6 \\
90 \%\end{array}$ & $\begin{array}{l}\text { LAD } \\
C x \\
\text { RCA }\end{array}$ & $\begin{array}{l}\angle A D \\
\text { (LIMA) }\end{array}$ & $\begin{array}{l}40 \mathrm{~mW}, 9 \mathrm{~mm} . \\
50 \mathrm{sec}\end{array}$ \\
\hline 6) & T. Y. & 58 & $M$ & UAP & $\begin{array}{lr}\text { LMT } & 15 \\
\text { LAD } & (7 \\
\text { CX } & 111 \\
& 112 \\
& 11 \\
\text { RCA } & (2\end{array}$ & $\begin{array}{r}75 \% \\
100 \% \\
90 \% \\
100 \% \\
100 \%\end{array}$ & $\begin{array}{l}\text { LAD } \\
\text { CX } \\
\text { RCA }\end{array}$ & $\begin{array}{l}\text { LAD } \\
\text { (SVG) }\end{array}$ & $\begin{array}{l}40 \mathrm{~mW}, 10 \mathrm{~mm}, \\
59 \mathrm{soc}\end{array}$ \\
\hline 7) & K. I. & 63 & $M$ & PIA & $\begin{array}{lr}\text { LMT } & 15 \\
\text { LAD } & 17 \\
\text { CX } & 112 \\
& 11 \\
& 11 \\
\text { RCA } & 11\end{array}$ & $\begin{array}{l}75 \% \\
75 \% \\
75 \% \\
90 \% \\
100 \%\end{array}$ & $\begin{array}{l}\text { LAD } \\
C x\end{array}$ & $\begin{array}{l}\text { LAD } \\
\text { (SVG) }\end{array}$ & $\begin{array}{l}40 \mathrm{~mW}, 24 \mathrm{~min} . \\
120 \mathrm{sec}\end{array}$ \\
\hline 8) & M. T. & 62 & M & PIA & $\begin{array}{rr}\text { LAD } \quad 16 \\
& 19 \\
C \times \quad 11 \\
\text { Cx } \\
114.15 \\
\text { RCA } \quad 12\end{array}$ & $\begin{array}{l}90 \% \\
500 \% \\
75 \% \\
90 \% \\
75 \%\end{array}$ & $\begin{array}{l}D_{1} \\
C x \\
R C A\end{array}$ & $\begin{array}{l}\text { LAD } \\
\text { (SVG) }\end{array}$ & $\begin{array}{l}40 \mathrm{~mW}, 20 \mathrm{~nm} . \\
94 \mathrm{sec}\end{array}$ \\
\hline
\end{tabular}

PIA : Postinfartion snoins
UAP: Unst toblo ongina poctoris
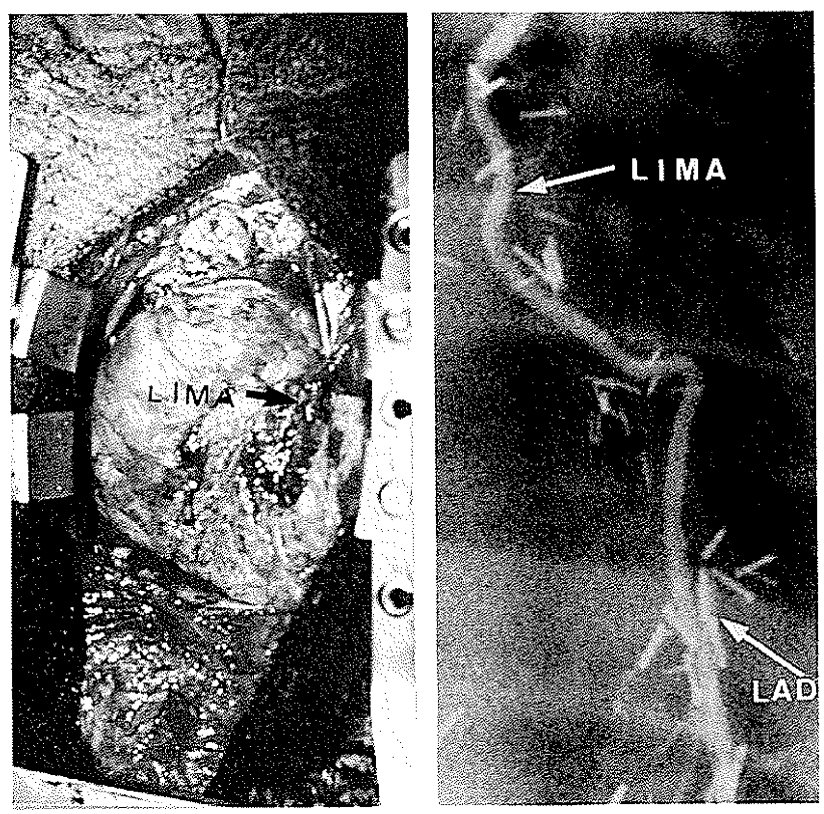

図 5 レーザーによる冠動胝バイバス術

(内胸動脈一前下行枝昒合、39歳、男)
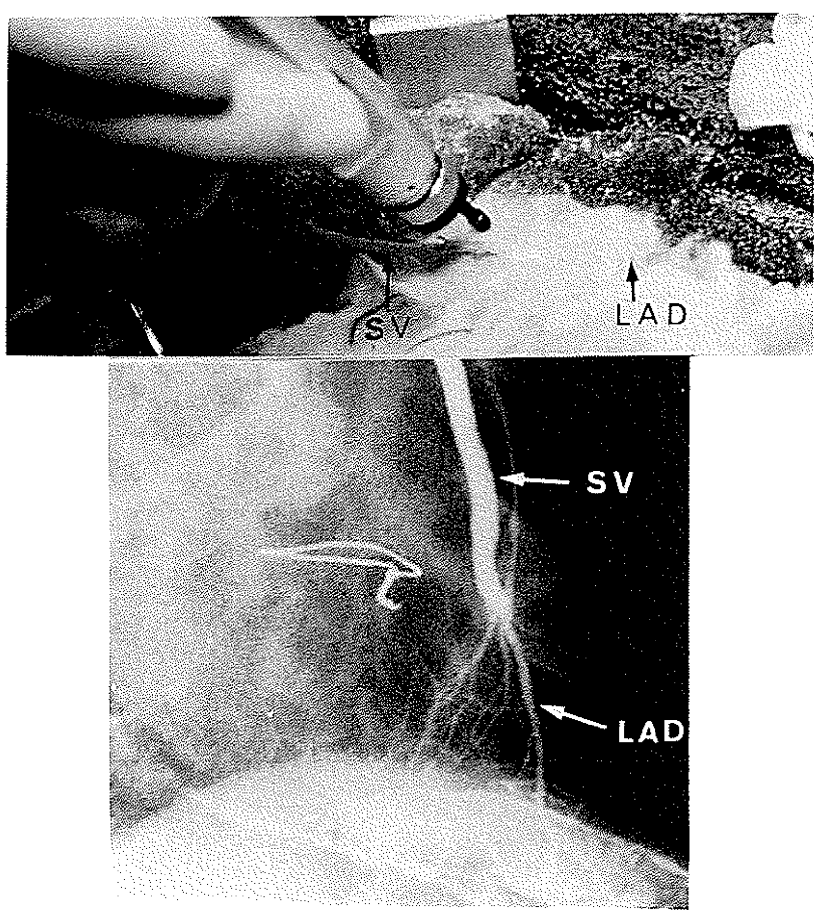

図 6 レーザーによる冠動脈バイバス術

（大伏在静脈一前下行枝吻合、58歳、男)

結 㖕

1) 低出力 $\mathrm{CO}_{2} レ$ ザーにより血管吻合の可能性が十分 に確認された。

2)沮管吻合に至適なレーザー照射の条件は出力20 40mW、照射時閾6〜12sec/mmであった。

3）臨束例 91 症例に対してレーザーによる血管吻会が 事施され、全例で艮好な成果がえられた。

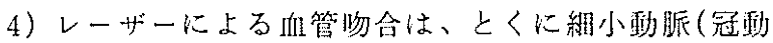
脈バイパスに招いてその効果が発䑾された。

5) 埒来的にみて、レーザーによる血管吻合は適応を 敨選することにより鰲及するものと考えられた。

文 献

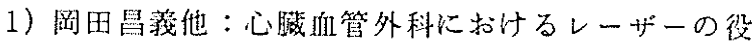
割、臨枺胸外科 $8: 535,1988$

2）岡田昌義他：レーザー応用に上る冠晌行再建術と 将来の展望、臨床朐外科 $42: 617,1989$

3) Okada $M$ et al : An alternative method of vascular an astomos is by laser ; Experimental and clinical study. Lasers Surg Med $7: 240$, 1987

4) White $R$ et al : Comparison of laser welded and sutured arteriotomies. Lasers Surg Med $6: 178,1986$

5) Okada $M$ et al: A new method of vascular anastomos is by laser. Surg Med Lasers 1:65, 1988

6）岡田舅義他：冠動脈疾患とレーザー手術、Heart Nursing $2: 123,1989$ 